\title{
Differentiating episodic ataxia type 2 from migraine: a case report
}

\author{
HJ Wu' ${ }^{1}$, MRCPCH, WL Lau', FHKAM (Paediatrics), FHKCPaed, Tina YC Chan², MB, ChB, \\ Sammy PL Chen², FHKAM (Pathology), FHKCPath, CH Ko ${ }^{1}{ }^{*}$, FHKAM (Paediatrics), FHKCPaed \\ ${ }^{1}$ Department of Paediatrics, Caritas Medical Centre, Hong Kong \\ ${ }^{2}$ Department of Chemical Pathology, Princess Margaret Hospital, Hong Kong
}

Hong Kong Med J 2020;26:526-7

*Corresponding author: koch@ha.org.hk

https://doi.org/10.12809/hkmj198306

\section{Case report}

A 17-year-old Chinese male was referred to Caritas Medical Centre, Hong Kong, in July 2015 for suspected migraine. His parents recalled onset of symptoms at age 11 years, at which time the child might suddenly hold onto rails for prolonged rest while climbing stairs, complaining of marked dizziness. The child sought no medical advice until age 17 years, when symptoms worsened to almost daily attacks. Each episode lasted from $>10$ minutes to a few hours and was usually precipitated by exercise or stress, but not by change in head position, neck movement, or fasting. During attacks, he could not walk along a straight line and experienced subjective generalised weakness. School biannual 9-minute run stamina assessment was prematurely aborted due to incapacitating dizziness. The dizziness was vertigo-like in nature and could be associated with bilateral temporal headache and nausea. He reported no tinnitus or dysarthria during attacks. No abnormal eye movement was observed by his parents during attacks. There was no history of aura, photophobia, chest pain, palpitation, numbness, visual impairment, hearing loss, tinnitus, or syncope. He functioned normally between attacks. Family history was negative for recurrent dizziness, migraine headache, or neurological disease. Neurological examination results were normal; there was no gaze-evoked nystagmus, cerebellar signs, or wide-based gait. Results of systemic examinations and laboratory tests, including complete blood picture, electrolytes, and thyroid function, were unremarkable. Electrocardiogram and computed tomography of the brain showed no abnormalities.

The patient was initially diagnosed with migraine variant but experienced no improvement after a 4-week trial of pizotifen prophylaxis. The predominantly exercise-induced prolonged vertigo spells, together with a relative paucity of pulsating lateralised headaches and lack of response to migraine treatment prompted the suspicion of episodic ataxia type 2 (EA2). Acetazolamide was started and the patient reported rapid clinical improvement with $>50 \%$ reduction in frequency and severity of attacks. The patient was asked to temporarily withhold the medication; symptoms returned instantly but responded to resumption of acetazolamide. Genetic testing revealed a novel heterozygous variant NM_001127222.1 (CACNA1A): c.5067+1 G>A and was likely to be pathogenic for EA2. This mutation was not found in the targeted genetic analyses of the parents and is likely de novo. During follow-up examinations, the patient reported that he could complete school 9-minute runs.

\section{Discussion}

The most common type of episodic ataxia is EA2 (Table), with an estimated prevalence of $<1$ in $100000 .^{1,2}$ In EA2, the characteristic ataxic spells can last from $>10$ minutes to hours. Triggers include physical exertion, emotional stress, alcohol, and caffeine. Disease onset is generally between age 5 and 20 years. Patients are usually symptom-free between attacks, but there may be interictal nystagmus and gradual development of a progressive ataxia syndrome. ${ }^{1}$ Episodic ataxia type 2 is caused by mutations in the $P / Q$-type voltage-gated calcium channel gene CACNA1A. It encodes the pore-forming subunit of the P/Q-type voltage-gated calcium channel, widely expressed throughout the central nervous system, particularly on presynaptic terminals of cerebellar Purkinje cells and granule layer neurones. It plays a key role in synaptic transmission. More than 80 EA2-associated mutations on CACNA1A have been reported. ${ }^{1,3}$

Clinical diagnosis of EA2 is challenging; the symptoms are often interpreted by primary care physicians as being due to more common conditions such as migraine, epilepsy, and vestibular disorders. Overlapping features with allelic conditions of familial alternating hemiplegia and spinocerebellar type 6 may result in phenotype variability including dysarthria, diplopia, tinnitus, hemiplegia and headache. ${ }^{1,3}$ Headache may appear without accompanying symptoms. The periodic appearance of ostensibly functional symptoms is often misinterpreted as migrainous; notably, 50\% of EA2 cases fulfil the International Headache Society criteria for migraine. ${ }^{3}$ In our patient, differentiating clues included identification of prolonged ataxic spells, 
TABLE. Clinical features of various types of episodic ataxias (EA)

\begin{tabular}{|c|c|c|c|c|c|c|c|}
\hline & EA1 & EA2 & EA3 & EA4 & EA5 & EA6 & EA7 \\
\hline OMIM & \# 160120 & \# 108500 & $\% 606554$ & $\% 606552$ & \# 613855 & \# 612656 & Unassigned \\
\hline Gene & KCNA1 & CACNA1A & Unknown & Unknown & CACNB4 & SLC1A3 & Mapped to $19 q 13$ \\
\hline Inheritance & Autosomal dominant & $\begin{array}{l}\text { Autosomal } \\
\text { dominant }\end{array}$ & $\begin{array}{l}\text { Autosomal } \\
\text { dominant }\end{array}$ & $\begin{array}{l}\text { Autosomal } \\
\text { dominant }\end{array}$ & $\begin{array}{l}\text { Autosomal } \\
\text { dominant }\end{array}$ & Sporadic & $\begin{array}{l}\text { Autosomal } \\
\text { dominant }\end{array}$ \\
\hline Onset age & $2-15 y$ & $5-20$ y & Variable & $23-60 y$ & $\begin{array}{l}\text { Early } \\
\text { adulthood }\end{array}$ & $\begin{array}{l}\text { First or second } \\
\text { decade (few } \\
\text { reports only) }\end{array}$ & Teens \\
\hline Duration of attacks & Seconds to minutes & Hours & Minutes & $\begin{array}{l}\text { Seconds to } \\
\text { hours }\end{array}$ & Hours & Hours to days & Hours to days \\
\hline Nystagmus & No & Usual & Occasional & Usual & Usual & No & No \\
\hline Myokymia & Yes & No & Yes & No & No & No & No \\
\hline $\begin{array}{l}\text { Acetazolamide } \\
\text { response }\end{array}$ & $\begin{array}{l}\text { Variable (may respond } \\
\text { to carbamazepine and } \\
\text { valproate) }\end{array}$ & Yes & Yes & No & Transient & No & Occasional \\
\hline Associated features & $\begin{array}{l}\text { Epilepsy } \\
\text { Neuromyotonia }\end{array}$ & $\begin{array}{l}\text { Epilepsy } \\
\text { Headache } \\
\text { Hemiplegia }\end{array}$ & $\begin{array}{l}\text { Epilepsy } \\
\text { Headache } \\
\text { Tinnitus }\end{array}$ & $\begin{array}{l}\text { Epilepsy } \\
\text { Tinnitus }\end{array}$ & Epilepsy & $\begin{array}{l}\text { Epilepsy } \\
\text { Headache } \\
\text { Hemiplegia }\end{array}$ & $\begin{array}{l}\text { Weakness } \\
\text { Dysarthria }\end{array}$ \\
\hline
\end{tabular}

exercise-induced attacks, and a lack of response to conventional migraine medications. Interictal ataxia and nystagmus, if present, may also help differentiate EA2 from migraine. The absence of positional dizziness and hearing loss helps differentiate EA2 from vestibular disorders. ${ }^{1}$ Electroencephalogram monitoring during attacks may help exclude epilepsy. As illustrated by our patient, dramatic improvement with acetazolamide may be diagnostic in doubtful cases. Notwithstanding the therapeutic response, paroxysmal exercise-induced movement disorders with acetazolamide responsiveness may also occur in glucose transporter defects such as GLUT1 deficiency. It is a rare metabolic defect of glucose uptake at the blood-brain barrier that may present as periodic movement disorder. The latter may have associated features of developmental delay, microcephaly, and carbohydrate responsiveness that are not present in EA2. The laboratory hallmark of GLUT1 deficiency is a low cerebrospinal fluid/ blood glucose ratio $<0.4 .{ }^{4}$ Episodic ataxia type 2 is differentiated from other hereditary episodic ataxias by the age of onset, spell duration, interictal nystagmus, and genetic locus (Table). ${ }^{1,2,4}$

Therapeutically, EA2 has a dramatic response to acetazolamide, with $50 \%$ to $75 \%$ of patients reporting improvement in episode severity and frequency at doses from 250 to $1000 \mathrm{mg}$ daily. ${ }^{1}$ Dose escalation is often limited by side-effects of paraesthesia, nephrocalcinosis, fatigability and hyperhidrosis. ${ }^{1,5}$ If acetazolamide is not tolerated, the potassium channel blocker 4-aminopyridine may improve symptoms. The mechanism is not fully understood; in animal models it has been shown to prolong the action potentials and restore the diminished precision of pacemaking in Purkinje cells. ${ }^{5}$

In summary, EA2 is a rare neurological disorder that can be misdiagnosed as migraine, epilepsy, or vestibular disorders, particularly in young children who cannot give a detailed history. Heightened physician awareness and early treatment can significantly improve patient quality of life.

\section{Author contributions}

All authors contributed to the concept or design of the study, acquisition of the data, analysis or interpretation of the data, drafting of the manuscript, and critical revision of the manuscript for important intellectual content. All authors had full access to the data, contributed to the study, approved the final version for publication, and take responsibility for its accuracy and integrity.

\section{Conflicts of interest}

All authors have disclosed no conflicts of interest.

\section{Funding/support}

This case report received no specific grant from any funding agency in the public, commercial, or not-for-profit sectors.

\section{Ethics approval}

The patient was treated in accordance with the tenets of the Declaration of Helsinki. The patient consented to publication of this article in a peer-reviewed journal.

\section{References}

1. Guterman EL, Yurgionas B, Nelson AB. Pearls \& Oysters: Episodic ataxia type 2 case report and review of the literature. Neurology 2016;86:239-41.

2. Jen JC, Graves TD, Hess EJ, et al. Primary episodic ataxias: diagnosis, pathogenesis and treatment. Brain 2007;130:2484-93.

3. Spillane J, Kullmann DM, Hanna MG. Genetic neurological channelopathies: molecular genetics and clinical phenotypes. J Neurol Neurosurg Psychiatry 2016;87:37-48.

4. Kipfer S, Strupp M. The clinical spectrum of autosomaldominant episodic ataxias. Mov Disord Clin Pract 2014;1:285-90.

5. Kalla R, Teufel J, Feil K, Muth C, Strupp M. Update on the pharmacotherapy of cerebellar and central vestibular disorders. J Neurol 2016;263 Suppl 1:S24-9. 